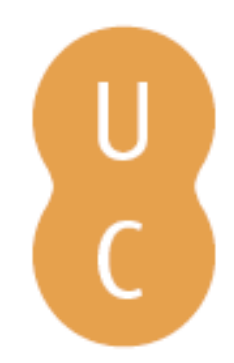

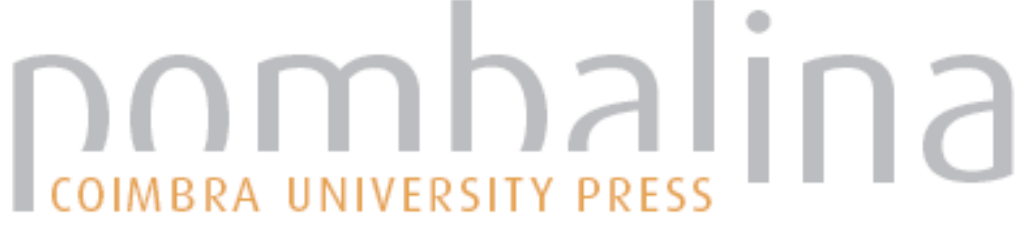

\section{Uma formação útil para a Literacia no novo contexto de Bolonha}

\author{
Autor(es): $\quad$ Braga, Maria Inês Peixoto
}

Publicado por: Imprensa da Universidade de Coimbra

URL

persistente:

URI:http://hdl.handle.net/10316.2/31905

DOI:

DOI:http://dx.doi.org/10.14195/978-989-26-0319-3_24

Accessed : $\quad$ 26-Apr-2023 13:30:34

A navegação consulta e descarregamento dos títulos inseridos nas Bibliotecas Digitais UC Digitalis, UC Pombalina e UC Impactum, pressupõem a aceitação plena e sem reservas dos Termos e Condições de Uso destas Bibliotecas Digitais, disponíveis em https://digitalis.uc.pt/pt-pt/termos.

Conforme exposto nos referidos Termos e Condições de Uso, o descarregamento de títulos de acesso restrito requer uma licença válida de autorização devendo o utilizador aceder ao(s) documento(s) a partir de um endereço de IP da instituição detentora da supramencionada licença.

Ao utilizador é apenas permitido o descarregamento para uso pessoal, pelo que o emprego do(s) título(s) descarregado(s) para outro fim, designadamente comercial, carece de autorização do respetivo autor ou editor da obra.

Na medida em que todas as obras da UC Digitalis se encontram protegidas pelo Código do Direito de Autor e Direitos Conexos e demais legislação aplicável, toda a cópia, parcial ou total, deste documento, nos casos em que é legalmente admitida, deverá conter ou fazer-se acompanhar por este aviso. 
Maria Manuel Borges

Elias Sanz Casado

Coordenação

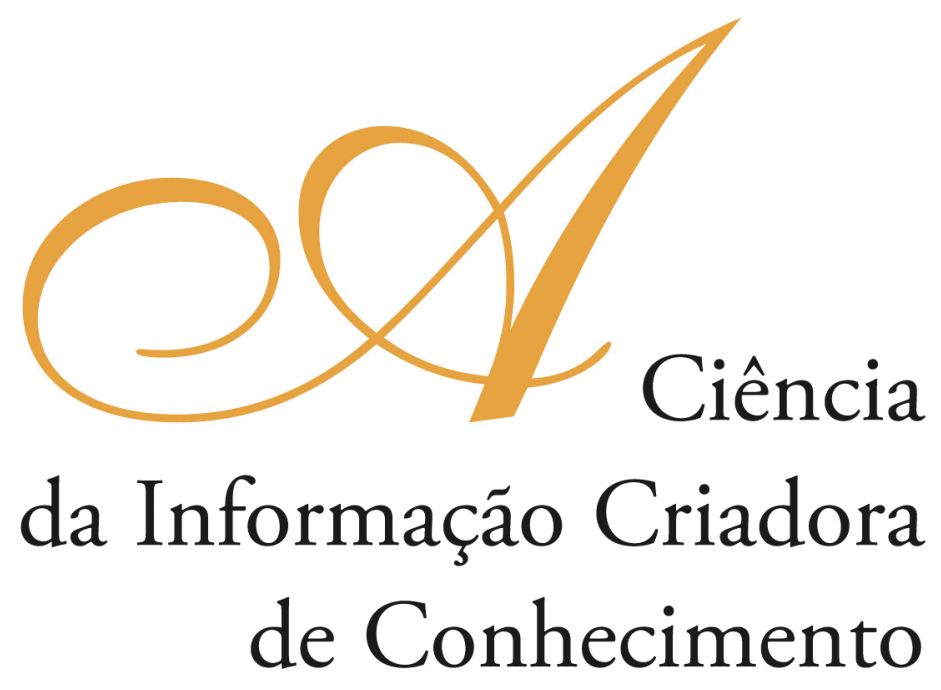

Vol. I

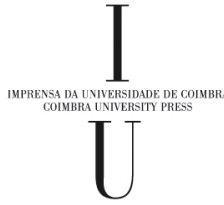

- COIMBRA 2009 


\title{
UMA FORMAÇÃo Útil PARA A LITERACia \\ NO NOVO CONTEXTO DE Bolonha
}

\author{
Maria Inês Peixoto Braga \\ Instituto Politécnico do Porto (Portugal)
}

\section{Resumo}

A Declaração de Bolonha (1999) obrigou a mudanças várias, reconfigurando os modelos formativos no espaço europeu do ensino superior, até 2010. A partir de 2006, em Portugal, com a criação e adequação dos cursos superiores existentes ao modelo de Bolonha, verificou-se uma generalizada redução da duração média dos diferentes ciclos de estudo e a definição de competências gerais e específicas para os cursos e estudantes.

Reflecte-se sobre a importância da literacia da informação, conceito evolutivo e abrangente, que se pode traduzir, sumariamente, em saber quando e porquê se tem uma necessidade informacional, onde encontrar a informação, como avaliá-la, usá-la e comunicá-la de forma ética, incluindo as competências tecnológicas, definição que se inscreve na interdisciplinar Ciência da Informaçáo e no comportamento informacional.

Destaca-se a vantagem de uma formação para a literacia da informação no ensino superior, a qual contribuirá, certamente, para dotar os estudantes das referidas competências e melhorálas.

Defende-se a necessidade de uma desejável inter-acção entre múltiplos agentes educativos, com destaque para a trilogia estudantes, bibliotecários e professores, sendo os primeiros encarados como protagonistas activos das suas aprendizagens e devendo ser dotados de competências de literacia da informação, factor determinante para o seu sucesso.

Quanto ao Bibliotecário, dotado de novas competências, entre as quais as tecnológicas, deve ser um facilitador do processo de formação para a literacia - preferencialmente integrada num projecto pedagógico e no currículo - articulando a sua acção educativa com estudantes e docentes. Corroborando a extensão educativa das Bibliotecas e aliando-a ao uso inevitável das novas tecnologias da informação e comunicação, sublinha-se o papel das Bibliotecas Digitais, que podem corresponder eficientemente aos anseios dos utilizadores no acesso a uma informação de qualidade, de forma cómoda, rápida, a baixo custo, com personalização dos serviços online, com inter-acção e socialização, através de ferramentas de edição colaborativa, típicas da Web 2.0.

\section{Abstract}

The Bologna declaration (1999) triggered a series of changes to reconfigure the educational models of the European higher education space by 2010. From 2006 Portugal witnessed a generalised reduction of the average duration of the study-cycles and the definition of general and specific skills for courses and students, resulting from the creation and adjustment of the higher education courses to the Bologna model.

This essay reflects upon the importance of information literacy. This evolving and comprehensive concept may be described as the ability to know when and why information needs occur, where to find information, how to assess it, use it and transmit it ethically using technological skills. This definition integrates the interdisciplinary area of Information Sciences which also comprehends informational behavior. Training of information literacy skills in higher 
education stands out as an advantage that will allow students to improve their skills and achieve full information literacy.

We defend the need for a desired interaction between the multiple education agents enhancing the trilogy composed by students, librarians and teachers. The first should be regarded as active protagonists of their learning process and provided with information literacy competences - a key factor of success.

The Librarian, having acquired new competencies, namely technologic, should act as a facilitator in the process literacy training - preferably integrated within a pedagogic and curricular project that articulates its educational action with both students and teachers. Supporting the educational extension of the Libraries and allying them to the inevitable use of the new information and communication technologies we should like to point out the role of the Digital Libraries. These can efficiently respond to the requirements of the users by comfortably, rapidly and inexpensively providing access to quality information, by customising on-line services, by allowing socialisation and interaction through collaborative edition tools of the web 2.0 .

\section{Bolonha: Um novo paradigma de educação no ensino superior e a definição de competências}

Se no próximo ano de 2010 se fecha um ciclo importante no âmbito da Declaração de Bolonha, já que esta é a data limite para os países subscritores da referida Declaração alterarem os seus modelos formativos de ensino superior no contexto europeu, julgamos que o trabalho iniciado em 1999, com a subscrição da Declaração por dezanove países europeus e em 2006, em Portugal, com a criação e adequaçáo dos cursos superiores ao novo modelo, náo se esgotará. Antes pelo contrário, deverá ser tarefa continuada, numa postura de melhoria contínua em que, apesar de algumas directrizes comuns aos vários países aderentes, cada instituição, curso, corpo docente e discente tem de encontrar, dialogando, os percursos adequados à prossecução das competências traçadas.

Um dos aspectos mais importantes no âmbito do Processo de Bolonha, para além da redução do número de anos para cada ciclo de ensino, é a mudança de concepção de um ensino centrado na transmissão de conhecimentos, por docentes, e a aquisição passiva dos mesmos, pelos alunos, para um sistema que valoriza a aprendizagem e o desenvolvimento de competências, visando garantir que os estudantes tenham mais aptidão para a vida profissional, idênticas condiçôes de formação e de integração profissional em relação aos países que integram o espaço europeu, bem como a aquisição do sistema europeu de créditos curriculares, com base no volume de trabalho desenvolvido pelos estudantes (ECTS - European Credit Transfer System)

Decorrente da Declaração de Bolonha, o estabelecimento do primeiro e segundo ciclos do ensino superior possibilitou o desenvolvimento de uma estrutura europeia de qualificaçóes na Área Europeia de Ensino Superior, iniciativa à qual se sucederam algumas outras, de âmbito nacional e internacional, tais como o projecto piloto Tuning e os Descritores de Dublin.

Relativamente à estrutura europeia de qualificaçóes para o ensino superior, ressaltemse alguns aspectos que recomendam que esta deve ser genérica, de modo a permitir uma comparabilidade entre diferentes estruturas de ensino, a nível internacional; que deve incentivar a mobilidade, descrever as qualificaçóes e ciclos em termos de resultados 
e enquadrar os perfis de formação - académico e profissional, entre outros aspectos. Quanto às competências, três tipos de resultados de aprendizagem estáo previstos - a nível dos conhecimentos, das capacidades e das competências pessoais e profissionais (MCTES-DGES, 2008 b).

Como instrumento orientador, que reforça algumas ideias centrais de Bolonha, é de assinalar o já referido projecto Tuning, implementado no ano de 2000, por um conjunto de universidades, sendo o seu objectivo a sintonização de estruturas educativas europeias, com destaque para umsistema de títulos de fácil reconhecimento e comparação e a adopção de um sistema de créditos, entre outros aspectos. Aliás, a designação "Tuning" (que significa "afinar" em termos musicais) representa a vontade de estabelecer directrizes para a compreensão mútua entre as diferentes universidades europeias envolvidas, assegurando a diversidade do ensino superior no contexto europeu e garantindo a autonomia das instituiçóes e entidades relacionadas com o mundo académico (MCTES-DGES, 2008 a).

Um dos contributos importantes do Tuning é a determinação de pontos de referência para as competências gerais e específicas de cada disciplina dos ciclos de estudo de diferentes áreas temáticas. Ora, essas competências descrevem os resultados da aprendizagem, ou seja, reflectem o saber de um estudante ou o que ele pode demonstrar, no final do processo de ensino-aprendizagem e são norteadoras seja da elaboração, seja da avaliação dos planos de estudo, possibilitando flexibilidade e autonomia no desenho dos mesmos e tendo resultado, do seu agrupamento, em grandes classes, o grupo das instrumentais, interpessoais e sistémicas. De referir ainda que, na base da sua definição, esteve uma auscultação efectuada a pessoal universitário, estudantes e empresas que se pronunciaram sobre aquelas que entendiam que os diplomados deveriam possuir. Sintomaticamente, das que foram reconhecidas como mais importantes a desenvolver, nos estudantes, a nível europeu, seja por empregadores, seja por diplomados, listam-se as relacionadas com as capacidades de: análise e síntese, aprendizagem, resolução de problemas, aplicação do conhecimento, adaptação a situações novas, preocupação pela qualidade, trabalho da informação e trabalho autónomo e de grupo (MCTES-DGES, 2008 a).

Quanto aos Descritores de Dublin, desenvolvidos pelo Joint Quality Iniciative Informal Group (JQI) - integrando membros de diferentes entidades de avaliação/ acreditação - e que visam uma caracterização geral, clara e comparada entre um $1^{\circ}$ e $2^{\circ}$ ciclo de estudos, a nível europeu, definem também quais os conhecimentos, competências, atitudes e valores para cada grau, respectivamente Licenciatura e Mestrado (o Doutoramento inclui uma versão preliminar, ainda), sendo assinaladas para os ciclos, as áreas comuns, a saber: conhecimento e capacidade de compreensão, aplicação de conhecimentos e compreensão, realização de julgamento/tomada de decisóes, comunicação e competências de auto-aprendizagem e diferindo os parâmetros e a complexidade incluídos em cada uma destas áreas comuns para cada ciclo (MCTESDGES, 2008 a).

Ora, como podemos verificar, muitas destas competências, estabelecidas no âmbito do modelo de Bolonha, coincidem ou estáo abrangidas por outras elencadas em vários estudos de referência sobre literacia da informaçáo, sendo oportuno destacar aqui algumas que Henry Jenkins e co-autores $(2006,7)$ indicam, tais como: participar no processo da inteligência colectiva; julgar (avaliando a fidedignidade e credibilidade de 
diferentes fontes de informação); recorrer à navegação transmedia (seguir o curso de histórias e de informação através de múltiplas modalidades) e ao networking (capacidade de pesquisar, sintetizar e disseminar informação) e ainda negociar.

\section{A literacia da informação: sua importância e contextualização}

A nível internacional, regista-se um reconhecimento da importância da literacia da informação, por parte de Governos, instituições e entidades profissionais, académicas e civis, levando a cabo investimentos tecnológicos e acçóes educativas que visam elevar os níveis de literacia da informação dos indivíduos.

Emblemática da projecção deste tema é a Declaração de Alexandria, de 2005, que reconhece que a competência informacional e aprendizagem ao longo da vida são os faróis da sociedade de informação e que são determinantes para o desenvolvimento, a prosperidade e liberdade dos indivíduos e naçóes (IFLA, 2005). Aliás, a sua importância e impacto são percepcionados por outras importantes associaçóes internacionais, de renome na área das Bibliotecas, como por exemplo a ALA - American Library Association -, bem como em conferências, relatórios, investigações internacionais e em curricula de importantes instituiçóes de ensino por esse mundo fora. Corroborando a importância do tema, podemos ainda citar a UNESCO, que celebra, de 2003 a 2012, a Década da Literacia das Naçóes Unidas (UNLD), que criou um portal dedicado ao tema e que tem vindo a implementar vários programas de combate à iliteracia e à info-exclusão.

Porque a literacia da informação é um conceito que tem vindo a evoluir ao longo dos tempos e que, na actualidade, vê reforçada a sua importância porque contribui para lidar, de uma forma mais adequada, com um problema premente, denominado excesso ou overload informacional, convirá assentar numa possível definição que se adeqúe à idiossincrasia da actual sociedade de informação.

Ora, neste pressuposto, se não restringirmos o referido conceito unicamente às capacidades básicas e estruturantes do saber ler, escrever e contar (próximas dos termos alfabetização, "letramento" em português do Brasil e numeracia) mas se recorrermos a uma definiçáo mais ampla de literacia da informação, tal como a capacidade de os indivíduos reconhecerem quando e porquê têm uma necessidade informacional, saberem onde encontrar a informação de que necessitam, através da consulta de várias fontes informacionais, independentemente do seu formato, saberem avaliá-la, usá-la e comunicá-la de forma ética (CILIP, 2008) recortaremos melhor a dimensão que queremos tornar visível neste estudo.

Como esta definição remete para a área do comportamento informacional, o qual integra a interdisciplinar Ciência da Informação (Silva, 2006, p.143), convirá evocar os estudos de Tom Wilson (1999) sobre o modelo de "information behavior" - comportamento informacional - o qual integra a Pesquisa da Informação ("information-seeking behavior"), na qual, por sua vez, está incluída a recuperação da Informação ("information search behavior"). Ora, este ciclo informacional adequase à definição de Literacia da Informação - reconhecimento de uma necessidade informacional, procura da informação numa série de fontes (o que pode provocar (in)sucesso), uso da informaçáo (em caso de sucesso), a qual pode ser usada pelo 
indivíduo que a procurou e ser comunicada e trocada com terceiros, reiniciando-se o ciclo, em caso de insucesso ou de não satisfação do utilizador da informação.

Este enquadramento do tema da Literacia na área da Ciência da Informação e do Comportamento Informacional já havia sido efectuado, no âmbito de um importante projecto de investigação sobre Literacia no Ensino Superior Português (Silva; Marcial; Martins, 2007). Igualmente, a definição de literacia informacional apresentada por Armando Malheiro da Silva como a "capacidade critica de buscar, avaliar, escolher $e$ usar informação nos mais diversos contextos" (SILVA, 2008, p.16), inscreve-se na área do comportamento informacional, relacionando-a ainda o autor com a questáo premente da inclusão digital, a qual implica o domínio de competências de Tecnologias da Informação e Comunicação.

$\mathrm{Na}$ sequência da mudança de um paradigma custodial, historicista, patrimonialista e tecnicista para um paradigma pós-custodial, informacional e científico (Silva, 2006, p.158-159), regista-se uma mudança fundamental no modo como o utilizador é visto, na medida em que, se no primeiro paradigma citado o centro das atençóes era o serviço ou sistema de informação, sendo o utilizador um destinatário passivo cujas necessidades informacionais seriam satisfeitas, de acordo com as possibilidades da instituição fornecedora da informação, já no novo paradigma é conferido ao utilizador um papel central e activo no processo de busca da informação.

Aliás, a importância dada ao receptor ou consumidor da informação já havia sido posta em evidência anteriormente, nos estudos de usos e de utilizadores da informação ("information uses") de Yves le Coadic (1997) acerca dos usos dos sistemas de informaçáo, tendo como centro das atençóes os utilizadores e rejeitando a análise dos sistemas de informação, sem serem considerados os receptores da referida informação. Para Coadic, no actual paradigma, com as novas técnicas e sistemas de informação online, o estatuto do utilizador modifica-se, tornando-se cada vez menos passivo, cada vez menos secundário, enfim, cada vez mais objecto central da atenção das instituiçôes orientadas para o receptor e expressivamente denominadas como "user-centered library".

Uma formação para a literacia da informação no ensino superior: uma acção sinergética

Depois de contextualizada a literacia da informação na área científica da Ciência da Informação, e porque, inevitavelmente, as competências informacionais dos indivíduos são ensinadas (formal e informalmente) sendo o acesso à literacia um Direito Humano, proclamado na Declaração Universal dos Direitos Humanos e consagrado na Constituição da República Portuguesa, integramo-la, por isso, inevitavelmente, também na área do Ensino, perspectiva segundo a qual o presente estudo também incidirá.

Julgamos que a aquisição de competências já enunciadas e recomendadas pelo modelo de Bolonha, bem como outras detalhadas em referenciais de literacia e vários estudos sobre o tema, será tanto melhor sucedida quanto melhor as instituiçóes de ensino superior souberem, de uma forma holística, proporcionar condiçóes para um trabalho articulado de formação para a literacia entre múltiplos agentes educativos, dos quais se destacam num núcleo central, os estudantes, bibliotecários e professores. Evidentemente que, para a aquisição das competências e sucesso dos diplomados em 
cada grau de ensino, para além da inter-acção destes elementos humanos, destacados no interior das referidas instituiçóes, deverão ser considerados os recursos materiais e tecnológicos do contexto educativo, bem como muitos outros intervenientes do exterior, tais como a acção dos governos, instituiçôes, associações profissionais, entidades ligadas à Educação e outras, famílias e amigos.

Como exemplo da necessidade de reunir sinergias e procedendo a uma análise da conjuntura alargada em que as questóes da Literacia se inscrevem, Eisenberg (2006) afirma como importante que administradores, pais e gestores reconheçam a importância da informação no processo de ensino-aprendizagem, do overload e qualidade informacionais como problemas sérios a abordar, dando relevo às questóes da Informação, Tecnologia da informação e literacia da informação.

De entre vários estudos consultados sobre o tema, apercebemo-nos de alguma convergência de autores no que concerne ao ensino da Literacia, apontando para pontos comuns tais como a adopção de um curriculum baseado no aluno, com conteúdos inter-disciplinares relacionados, num estreito trabalho de parceria entre os referidos agentes educativos. É generalizado o destaque dado ao aluno como motor das suas aprendizagens, começando a surgir, no contexto internacional, programas de formação específicos para o ensino da Literacia, cabendo ao Bibliotecário implementá-los e desenvolvê-los, fazendo-se jus, desse modo, à designação, cada vez mais frequente, de Professor Bibliotecário e a uma nova função que este deve exercer no âmbito do seu exercício profissional.

\section{O papel educativo do bibliotecário em Programas de Literacia da Informação}

É nesta perspectiva que se situa Dudziak (2005), a qual encara o aluno como o protagonista do processo de ensino-aprendizagem, sendo o bibliotecário e docentes vistos como facilitadores, coadjuvantes que não ensinam mas "aprendem com", numa construção conjunta de competências, conhecimentos e valores. Para a autora, a cooperação entre docentes e bibliotecários, com a partilha de desejos e objectivos comuns, é fundamental para o sucesso de um programa de literacia da informação, integrado num projecto pedagógico e no currículo.

Quanto ao papel educativo do bibliotecário, a autora refere a necessidade de divulgação da importância da competência em informação na formação dos alunos para uma efectiva colaboraçáo dos docentes, a parceria entre o docente e o estudante, o envolvimento com a comunidade, o estabelecimento de parcerias e co-responsabilidades, a disponibilidade e tempo para o diálogo e para uma escuta atenta. Destacamos ainda dos pontos referidos, a importância do desenvolvimento das chamadas "habilidades" junto dos alunos, a criação de oportunidades, a flexibilidade do programa com integração de contributos dos outros agentes educativos, a criação de um ambiente positivo de aprendizagem, a promoção da autonomia e finalmente, a avaliaçáo dos alunos conforme as suas capacidades e esforços.

Também sobre o papel educativo do bibliotecário em programas de formação de literacia, (Eisenberg, 2006) destaca como essencial a difusão de uma mensagem de força sobre o papel dos referidos programas e do "teacher-libraran", a implementação de programas de grande qualidade, activos, envolventes e com significado e, finalmente, 
que estes devem estar no centro do currículo escolar e de importantes iniciativas da instituição.

\section{As Bibliotecas digitais como formadoras activas no âmbito da Literacia no ensino superior}

A nível europeu, no contexto de Bolonha, já há alguns casos em que é visível esta articulaçáo de diferentes agentes educativos, com destaque para as Bibliotecas e seus Profissionais.

Procedendo a uma análise sobre a situação de inovação europeia, fundada em programas de apoio da Comissáo Europeia e em receitas próprias, há universidades que dão efectivo apoio aos seus estudantes, numa articulação concertada e convergência entre serviços e entidades diversificados, no seio da instituição de ensino. Peter Brophy (2008) refere os casos de países bem sucedidos em experiências de ensino que pressupóem partilha, cooperação e implementação de serviços inovadores, a nível de Bibliotecas, como a Grécia, a Alemanha, a Finlândia e a Dinamarca. Em todos os casos, a presença das bibliotecas digitais e o papel dos Profissionais que as dirigem no âmbito da formação, também a distância, são muito importantes. De referir que a cooperação de que já falámos anteriormente não se restringe, nalguns casos, apenas ao micro-cosmos das instituiçôes mas, a nível das bibliotecas digitais também a programas nacionais e internacionais que visam uma rentabilização dos custos e uma partilha de recursos. Destaquemos, dentre os casos referidos pelo autor, o caso da Grécia que, perante as restriçóes orçamentais para aquisiçôes, procedeu à subscrição colectiva, a nível das universidades nacionais, de periódicos online cuja consulta é crescente. No caso da Finlândia, três universidades juntaram-se para partilhar um centro para apoio a actividades de desenvolvimento de ensino, de orientação e formação a nível das Tecnologias da Informação e Comunicação, de produção de materiais pedagógicos, como vídeos e animaçóes para uso no Moodle e apoio na distribuiçáo de telemóveis e PDA's.

Sobre um outro importante projecto relacionado com um centro de ensinoaprendizagem, a nível do ensino superior, com incidência na área da Literacia da Informação na Manchester Metropolitan University (MMU), relatam-nos Bob Glass e Jillian R. Griffiths (2008) que ele funciona com uma equipa constituída por profissionais de Biblioteca, académicos, conselheiros de educaçáo e investigadores, com contactos estreitos com o pessoal da Biblioteca e outros serviços de apoio ao ensino, realizando esta equipa várias actividades. Contam-se, dentre elas, a produção de cinco objectos de estudo reutilizáveis, um dos quais - Info Skills (WeCT) - criado em colaboração com as Bibliotecas da Universidade, a elaboração de posters e seminários, participação em conferências internacionais da área das Bibliotecas e do ensino e cooperação europeia com várias universidades, incluindo inter-acçáo entre as Bibliotecas universitárias e públicas. Ainda, com o objectivo de proceder à avaliação do grau de literacia da informação dos alunos, foi aplicado um teste, com questôes que visam a avaliação de diferentes competências, permitindo os resultados adoptar estratégias para a melhoria de áreas que apresentam piores resultados.

Também Sara Marsh (2008) fala do caso inglês, com relato da experiência do serviço de apoio aos estudantes a nível académico, pessoal e profissional - Learner Support Services (LSS) - da Universidade de Bradford cuja estrutura orgânica original, apesar 
de pressupor um funcionamento articulado de serviços institucionais distintos, como a Biblioteca e Centro de Computadores, os Serviços de Gestão da Informação e os Serviços de Desenvolvimento da Carreira, viu reforçada a cooperação e suas vantagens devido a uma mudança funcional. A título de exemplo desta missão conjunta de formação global dos estudantes, em que o pessoal da Biblioteca tem a seu cargo o aumento das competências de literacia, contam-se actividades como seminários e workshops recobrindo competências inter-pessoais e áreas como a gestão do tempo, relações com pessoas difíceis, condução de reunióes e gestão do stress.

Igualmente, na Universidade de Birmingham, decorreu, entre Junho de 2006 e Fevereiro de 2007, um interessante projecto no âmbito do apoio à promoção da Literacia intitulado BRUM - Birmingham Re-usable Materials - (Graham, 2008), liderado por dois Bibliotecários, com a colaboração de quatro professores que integravam os objectos produzidos no curriculum e recolhiam as opinióes qualitativas dos alunos através de inquéritos. Os quinze objectos produzidos foram alojados na página Web, usados em aulas e institucionalmente, em ambientes virtuais de aprendizagem. Desta experiência, que teve muito sucesso, graças à sua inter-actividade, a qual despoletou, junto dos estudantes, comportamentos activos relacionados com o desenvolvimento do pensamento e resposta a questóes, retêm-se algumas outras vantagens como o anonimato, a imediaticidade do feed-back conferidos pelo sistema e a flexibilidade no acesso aos materiais disponibilizados na internet. Outra vantagem dos objectos pedagógicos produzidos prende-se com o seu uso efectivo em contextos pedagógicos e possibilidade de adaptação, a sua utilidade, bem como as semelhanças do seu design e materiais com os que os estudantes usam normalmente nos seus espaços sociais online, como vídeos, clips, música, texto e links da Web. Desta experiência se pode concluir que, como os jovens gostam e usam as NTIC's, o desafio está em usá-las no ensino, melhorando as suas competências de literacia, através do treino e exploração, indo ao encontro das suas expectativas e necessidades.

Se uma das respostas possíveis aos desafios colocados por Bolonha passa por projectos pedagógicos conjuntos e pelo uso de ferramentas da Web 2.0, cumprirá também, de forma sistemática, às Bibliotecas do ensino superior (e outras instituiçôes e entidades) estarem necessariamente atentas e acompanharem as alterações que um novo modelo educativo pressupóe, efectuando uma necessária planificaçáo estratégica, tal como por exemplo a que foi levada a cabo pelo Serviço de Biblioteca e Documentação da Universidade Politécnica da Catalunha, através do Programa Aprèn 2007-2010 (Dídac,M., López-Vivancos,M., Sunyer-Lázaro,S.\& Vives-Gràcia, J.,2007). Neste projecto visa implementar-se, entre outras medidas, um maior desenvolvimento das TIC nas Bibliotecas, a criação de áreas de auto-aprendizagem de línguas e informática, a formação de formadores, a digitalização de colecçóes, a implementaçáo de serviços personalizados e online ou a criação da biblioteca digital como suporte ao e-learning. Ainda de referir a criação de repositórios em que são alojados os materiais educativos e trabalhos académicos para dar apoio ao e-learning e aumentar a visibilidade da produção científica dos investigadores na net, a personalização dos serviços em linha, a vertente da socialização, através de estratégias relacionadas com a " biblioteca 2.0". Tal como no caso inglês, uma das missóes das bibliotecas da U.P.C. é tornar-se um centro activo de recursos e serviços de qualidade para dar resposta às necessidades de aprendizagem, investigação e 
formação contínua da comunidade universitária, transformando a B.D. num portal de recursos e serviços personalizados.

Já em 1999, Murilo Bastos da Cunha apontava algumas das funcionalidades das B.D., a nível do ensino superior, tais como tutoriais baseados em computador, caracterizados como instrumentos educacionais úteis para informações básicas e gerais sobre a biblioteca, instruçóes sobre pesquisas para trabalhos académicos e para aquisição de competências de pesquisa. Com o overload informacional, este autor refere a importância do ressurgimento da difusão selectiva da informação não restrita aos documentos tradicionais, por exemplo, o noticiário em linha, jornais, rádio e televisão, mercado das bolsas de valores, entre outros, o que pode ser uma mais-valia para a biblioteca universitária, extrapolando os assuntos técnico-científicos e colaborando nas outras necessidades informacionais diárias.

Também Maria Manuel Borges (2001), não vendo a B.D. como uma ameaça mas como uma forma de ultrapassar problemas que a Biblioteca tradicional apresenta, tal como a necessidade de partilha do mesmo contexto espacio-temporal entre o utilizador e o objecto analógico, assinala a grande vantagem de a B.D. garantir sempre o encontro do leitor com o objecto digital, desde que este esteja disponível e desde que os canais de comunicação ou redes não apresentem problemas, possibilidade que, segundo o nosso entender, deverá ser explorada estrategicamente pelas instituições de ensino superior (e não só) para satisfazerem eficazmente os seus utilizadores que buscam uma resposta às suas necessidades informacionais, $o$ mais rápida e comodamente possível e com os menores custos, aliando o prazer de uma comunicação virtual que os faça sentir mais participativos e implicados nas suas aprendizagens.

Os projectos anteriormente referidos e tantos outros que se poderiam citar provam a necessidade de uma nova forma de actuação para as Bibliotecas e seus profissionais que, na sua formação, devem ter competências acrescidas, nomeadamente a nível das TIC, tendo como objecto central uma formação holística dos estudantes, a excelência do ensino, através da colaboração e parceria em equipas multidisciplinares, e promovendo o uso e formação a nível das TIC. Evidentemente que todas as boas práticas pressupóem dotaçôes financeiras, medidas de gestão institucionais e políticas educacionais que contribuam para a visibilidade de um projecto educativo sustentado e resultados de excelência.

\section{Conclusão}

No quadro de Bolonha e de um desejável processo, amplo e convergente, da Educação (para e com a Literacia) em que o Estado, as instituiçóes formadoras de ensino, a sociedade civil e as famílias devem actuar sinergeticamente, através de investimentos e políticas adequadas, destaca-se uma nova função formadora para os Bibliotecários. Estes, no quadro de um projecto educativo sustentado e implementando projectos de formação, têm de ter novas competências, com destaque para as relacionadas com a Literacia dos Media, para também as transmitirem ou consolidarem de forma eficaz junto dos estudantes com quem devem estabelecer, doravante, uma relação mais próxima e activa, de facilitação e orientação, trabalhando em parceria com eles e 
seus docentes. A nível da formação superior na área da Ciência da Informação, há já linhas orientadoras para traçar um perfil de competências para os novos Profissionais da Informação (European Council of Information Associations, 2005), sendo nossa convicçáo de que em Portugal a formaçáo superior confira a estes diplomados competências nesse sentido.

No actual paradigma pós-custodial, informacional e científico, lembremos a importância das Bibliotecas centradas na resoluçáo das necessidades informacionais dos seus utilizadores, desenvolvendo uma acção formativa junto deles, seja através duma relação presencial - mais típica das bibliotecas ditas tradicionais -, seja numa inter-acção mediada pelas TIC - que se coaduna com as bibliotecas digitais ou com o conceito mais recente de Bibliotecas 2.0, as quais permitem novas posturas e formas de comunicação entre os serviços de informação e os utilizadores, bem como entre os utilizadores que podem inter-agir virtualmente entre si (Amândio, 2007; Bradley, 2008). Este novo conceito de bibliotecas permite a alteração de um indesejável modelo de comportamento estático e acrítico dos utilizadores, anteriormente consumidores passivos da informação, implicando-os, agora também, como possíveis produtores da informação ("prosumers"), de forma activa, na construçáo de um projecto comum de bom serviço, baseado no espírito de parceria e partilha da comunicação, através das novas tecnologias.

No presente quadro de transição, em que a tecnologia invade os sistemas de informação mas em que as bibliotecas físicas ainda permanecem e hão-de certamente permanecer por muito tempo, talvez seja mais oportuno pensar-se em termos de uma biblioteca híbrida, conceito que surgiu no decurso de investigaçóes realizadas no âmbito da biblioteca digital na Inglaterra e que se pode caracterizar como a que alberga recursos de informação impressos e digitais, acedíveis local ou remotamente (Chowdhury, Chowdhury, 2004). Provavelmente, devido à extrema juventude das bibliotecas digitais, esta postura prudencial, de conciliação, que a biblioteca híbrida encerra, será a mais adequada para uma adequada conservação, preservação e divulgação da diversidade do património informacional bem como a que melhor responderá à missão de formação que cabe aos Bibliotecários, doravante, desenvolver.

Inevitavelmente condicionadas pelas leis da ciber-cultura- reconfiguração, emissão generalizada e conexão, a sociedade e a Escola devem acompanhar a transição dos modos de representação, não devendo esta alteração ser entendida só como uma mera passagem do meio analógico para o meio digital mas também como uma alteração a nível comportamental, a qual pressupóe novas possibilidades de construção da identidade e de socialização. Esta mudança, alvo de reflexão na obra Page to Screen (Snider, I. (Ed.), 1997 ) - pressupóe que os utilizadores das novas tecnologias devam conhecer e lidar criticamente com uma nova forma de leitura e apropriação do mundo, dos outros, de si próprios e do texto, ou melhor, do hiper-texto, sendo tácita a ideia de que o poder, actualmente, está muito estritamente associado ao acesso, à familiaridade e destreza do uso das novas tecnologias para fins de literacia.

Retomando o contexto educativo e as mais-valias de uma planificação estratégica das Bibliotecas e dos programas de formação devidamente alicerçados numa global acção educativa adequada à realidade da Sociedade, sublinhemos a motivação dos jovens e o leque vasto de competências de literacia que estes devem desenvolver, tais como as tecnológicas, o pensamento crítico nomeadamente face aos Media, a resolução 
efectiva de problemas do seu quotidiano nos contextos pessoais sociais e profissionais, a autonomia, a capacidade de aprender a aprender e a aprendizagem ao longo da vida, entre outras competências transversais, definidas convergentemente para os aprendentes do ensino superior, no quadro de Bolonha.

Em síntese, formando os estudantes para o uso responsável e ético da informação, assim se preparam, para o futuro, cidadãos participativos e co-responsáveis na construção de uma sociedade mais livre, justa e democrática.

\section{Referências bibliográficas}

Amândio, M. J. (2007). Literacia de informação 2.0 nas bibliotecas municipais de Oeiras: Uma abordagem ao Programa Copérnico. Actas do Congresso Nacional de Bibliotecários, Arquivistas e Documentalistas, 9. Retrieved October 30, 2008, from http://badinfo.apbad. pt/Congresso9/COM53.pdf

Borges, M. M. (2002). De Alexandria a Xanadu. Coimbra: Quarteto Editora.

Borges, M. M. (2001). A Biblioteca digital: da imaginação em exercício ao exercício da imaginação. Páginas a\&b. 7, 7-67.

Bradley, P. (2008). How to use web 2.0 in your library. London: Facet Publishing.

Braga, I. (2006). O Processo de Bolonha e a inevitável mudança na área da Ciência da Informação. Cadernos BAD, 1, 56-67.

Brophy, P. (2008). The integration of physical and virtual environments to support HE learners: A european perspective. In Weaver, M. (Ed.) - Transformative learning support models in higher education (pp. 119-133). London: Facet Publishing.

Chowdhury, G., \& Chowdhury, S. (2004). Digital libraries definition and characteristics. In Introduction to digital libraries (pp. 1-15). London: Facet Publishing.

CILIP.(2008). Information Literacy: definition. In Policy and advocacy. Learning. Information Literacy. Retrieved July 30, 2009, from http://www.cilip.org.uk/policyadvocacy/learning/ informationliteracy/definition/default.htm

Coadic, Y. (1997). Usages et Usagers de l'Information. Paris: Nathan

Cunha, M. B. (1999). Desafios na construção de uma biblioteca digital. Ci.Inf., 28 (3) 257-268. Retrieved January 15, 2009, from http://www.scielo.br/scielo.php?script=sci_ arttext\&pid $=S 0100-19651999000300003 \& \operatorname{lng}=$ en $\& n r m=i s o \& t \operatorname{lng}=p t$

Dídac, M., López-Vivancos, M.,Sunyer-Lázaro, S. \&Vives-Gràcia, J. (2007). La planificación como estratégia en las bibliotecas de la UPC. El professional de la información. 16, (4), 345-354. Retrieved January 15, 2009, from http://web.ebscohost.com/ehost/pdf?vid=2\&h $\mathrm{id}=103 \&$ sid=bddcf2ae-30e7-4774-b87a-c1 fea8d59602\%sesionmgr3

Dudziak, E. A. (2005). Competência em informação: melhores práticas educacionais voltadas para a information literacy. Retrieved October 30, 2008, from http://eprints.rclis.org/ archive/00005018/01/166_DUDZIAK_CBBD_2005b.pdf

Eisenberg, M. (2006). Three roles for the 21st-century teacher-librarian. CSLA Journal, 29 (2), 21-23. Retrieved January 25, 2009, ffrom http://web.ebscohost.com/ehost/pdf?vid=43\&hi $\mathrm{d}=3 \&$ sid=f82c6ca4-51ab-47c1-8a08-006181958e4c\%40sessionmgr 107

European Council of Information Associations (2005). Euro-Referencial I-D. Lisboa: INCITE, 2005. 
Garcia Marco, F. J. (2002). La biblioteca digital in Lopez Yepes, J. (Ed.). Manual de ciências de la documentacion (pp. 651-670). Madrid: Ediciones Pirámide.

Glass, B., \& Griffiths, J. R. (2008). An introduction to the Learn Higher Centre for Teaching and Learning (CETL), with particular reference to the information literacy learning area and its work on information literacy audits at Manchester Metropolitan University. In Brophy, P., Craven, J.; Markland, M. Libraries without walls 7: Exploring 'anytime', 'anywhere' delivery of library services. (pp. 91-103). London: Facet Publishing.

Graham, N. (2008). Re-usable learning objects for information literacy: are they practicale?. In Brophy, P., Craven, J.; Markland, M. Libraries without walls 7: Exploring 'anytime', 'anywhere'delivery of library services. (pp. 81-89). London: Facet Publishing.

IFLA (2005). Declaraçáo de Alexandria sobre competência informacional e aprendizado ao longo da vida. Retrieved January 20, 2009, from http://sebenta.janjos.com/index. php/Declara\%C3\%A7\%C3\%A3o_de_Alexandria

Jenkins, H. , Clinton,K., Purushotma, R.,. Robison, A., Weigel M. (2006). Confronting the challenges of participatory culture: media education for the 21st century. Retrieved July 30, 2009, from http://digitallearning.macfound.org/atf/cf/\%7B7E45C7E0-A3E0-4B89AC9C-E807E1B0AE4E\%7D/JENKINS_WHITE_PAPER.PDF

Marsh, S. (2008). From learning to learner: the role of learner support services in the Bradford student experience. In Weaver, Margaret (Ed.) - Transformative learning support models in higher education (pp. 51-65). London: Facet Publishing.

M.C.T.E.S (2008). Declaraçáo de Bolonba. Retrieved July 30, 2009, from http://www.mctes. $\mathrm{pt} /$ archive/doc/Bolonha.pdf

M.C.T.E.S \& D.G.E.S.. (2008 a). Descritores de Dublin. Retrieved July 30, 2009, from http://www.dges.mctes.pt/DGES/pt/Estudantes/Processo+de+Bolonha/Objectivos/ Descritores+Dublin/

M.C.T.E.S \& D.G.E.S..(2008 b). DIMENSĀO EUROPEIA DO ENSINO SUPERIOR. Retrieved July 30, 2009,from http://www.dges.mctes.pt/DGES/pt/Estudantes/Processo+de+Bolonha/ Objectivos/Dimens\%C3\%A3o+Europeia+do+Ensino+Superior/

Pinto, L., Ochôa, P. (org) (2006). A imagem das competências dos profissionais de Informaçáo-Documentaçáo:relatório. Retrieved October 8, 2009, from http://files.incite. pt/RelatorioOP-ID.pdf

Ribeiro, F. (2006). Um modelo formativo em Ciência da Informação, de feição europeia e adequado a Bolonha: o caso da Universidade do Porto. Cadernos BAD. 1, 16-27.

Roberts, S., \& Stewart, J. (2008). Towards the holistic university: working collaboratively for student learning. In Weaver, Margaret (Ed.). Transformative learning support models in higher education (pp. 19-31).London: Facet Publishing

Silva, A., \& Ribeiro, F. (2002). Das "ciências documentais" à ciência da informação: ensaio epistemológico para um novo modelo curricular. Porto: Ediçóes Afrontamento.

Silva, A. (2006). A informaçáo: da compreensáo do fenómeno e construçáo do objecto científico. Porto: Ediçôes Afrontamento, CETAC.

Silva, A. M., Marcial, V., \& Martins, F. (2007). A literacia informacional no espaço europeu de ensino superior: Fundamentos e objectivos de um projecto em várias fases. Actas do Congresso Nacional de Bibliotecários, Arquivistas e Documentalistas, 9. Retrieved October 30, 2008, from http://badinfo.apbad.pt/Congresso9/COM31.pdf 
Silva, A. et al. (2008). Espaço Europeu de Ensino Superior e a literacia informacional: Conceitos e objectivos de um projecto de pesquisa aplicada em ciência da informação. Páginas $\boldsymbol{a} \mathfrak{b} \boldsymbol{b}$, $1,103-123$.

Silva, A. (2008). Inclusão digital e Literacia informacional em Ciência da Informação. PRISMA. COM. 7, 16-43. Retrieved March, 19, 2009, from http://prisma.cetac.up.pt/16_Inclusao_ Digital_e_Literacia_Informacional_em_Ciencia_da_Informacao_Armando_Malheiro_Silva. pdf

Snider, I. (Ed.). (1997) Page to screen: taking literacy into the electronic age. London: Routledge.

WILSON, T. (1999). Models in information behavior research. Journal of Documentation.

55, 3, 249-270. Retrieved March, 19, 2009, from http://informationr.net/tdw/publ/ papers/1999JDoc.htm> 